\title{
The Motives behind Cantor's Set Theory - Physical, Biological, and Philosophical Questions
}

\section{José Ferreirós}

Universidad de Sevilla

\section{Argument}

The celebrated "creation" of transfinite set theory by Georg Cantor has been studied in detail by historians of mathematics. However, it has generally been overlooked that his research program cannot be adequately explained as an outgrowth of the mainstream mathematics of his day. We review the main extra-mathematical motivations behind Cantor's very novel research, giving particular attention to a key contribution, the Grundlagen (Foundations of a general theory of sets) of 1883, where those motives are articulated in some detail. Evidence from other publications and correspondence is pulled out to provide clarification and a detailed interpretation of those ideas and their impact upon Cantor's research. Throughout the paper, a special effort is made to place Cantor's scientific undertakings within the context of developments in German science and philosophy at the time (philosophers such as Trendelenburg and Lotze, scientists like Weber, Riemann, Vogt, Haeckel), and to reflect on the German intellectual atmosphere during the nineteenth century.

Mathematical theories have a strong internal structure and, in the nineteenth and early twentieth centuries, their development has tended to be stimulated mainly by internal questions. As the structure of these theories grew increasingly complex, it becomes more difficult to find external motives that may have influenced mathematical research. Cantorian set theory, in particular, seems to be the quintessential example of an abstract, purely mathematical development, originating exclusively from intra-mathematical questions. But our review of this case will show that, indeed, extra-mathematical motives seem to have played an important role.

In a letter of September 1884 to his friend Gösta Mittag-Leffler, the mathematician and founding editor of Acta Mathematica, Cantor offered a surprising account of the motives behind his work on set theory:

I am also working on the application of set theory to the natural theory of organisms, where we cannot apply traditional mechanical principles.... For that purpose it was necessary to create completely new mathematical tools, which in essence can be found in those parts of set theory that I have developed. I have been working on this project of a precise deepening into the essence of everything organic for 14 years already. It constitutes the real motivation why I have confronted, and during this time have never lost 
sight of, the fatiguing enterprise of investigating point-sets, which promises little recognition. ${ }^{1}$

Can we take this fragment at face value, inferring that Cantor's set theory was motivated by expectations of biological applications? What is the evidence that Cantor was (as he states, from 1870) involved with such thoughts? And how does this help us understand the development of Cantorian set theory? Such are the questions I intend to explore here.

There are non-trivial problems with an interpretation of that letter, since it was written after Cantor's first manic-depressive crisis (spring of 1884). His surprising account could conceivably be a side-effect of the crisis, a novel development in his thinking, just like the strong interest he developed in the hypothesis (then in vogue) that Francis Bacon was the real author of Shakespeare's dramas. ${ }^{2}$ Therefore it is particularly noteworthy that we find evidence for Cantor's interest in natural-philosophical questions stemming from the pre-crisis period, particularly in his path-breaking work of 1883, the Grundlagen einer allgemeinen Mannichfaltigkeitslehre (Foundations of a general theory of sets).

Our topic obviously connects with the theme of Naturphilosophie and the emergence of a national scientific style in nineteenth-century Germany, a style in which speculative tendencies and the influence of philosophy were two characteristic traits. In this regard, the present study can be put in line with previous ones on the relations between embryology and Naturphilosophie, as well as studies showing the relationship between the botanical work of Schleiden and the neo-Kantian philosopher Fries, Grassmann's Ausdehnungslehre and the idealistic philosophy of Schleiermacher, Fechner's science and his philosophical ideas, Riemann's path-breaking contributions and the philosophy of Herbart. For reasons ranging from general cultural tendencies to institutional affiliation, German scientists lived in an environment in which the "two cultures" were particularly close.

In exploring our topic, I shall pursue the following path. We will first review the development of Cantor's mathematical ideas with an eye toward the main problems he was exploring and the contemporary reception. In sections 1 and 2, I argue that he did not pursue big open mathematical problems, but rather forged new problems while pursuing quite speculative interests. Section 3 will examine the main source of evidence for the influence of natural-philosophical ideas in the development of Cantor's set theory, his Grundlagen (1883). With this background, section 4 analyzes Cantor's philosophical and religious views as of 1870, and section 5 depicts the broader intellectual context at the time with special attention to the German debate on materialism. Throughout this paper, a special effort is made to place Cantor's scientific undertakings within the general context of developments in German science and

\footnotetext{
${ }^{1}$ Cantor to Mittag-Leffler, 22 September 1884, Cantor 1932, 202.

${ }^{2}$ See the detailed study in Purkert and Ilgauds 1987.
} 
philosophy at the time. Sections 4.2, 5, and 6 contain most of the contextual material, touching on the work of philosophers like Trendelenburg and Lotze, or scientists like Weber, Fechner, Riemann, Vogt, and Haeckel.

Although the great mathematician did not emphasize the extra-mathematical motivation for his work before 1883, there is enough evidence to sustain the view that those interests (including the project of an organicistic understanding of Nature) were in place around 1870, and indeed they came out more and more explicitly from $1878 .{ }^{3}$ Having established this, section 6 presents the main examples Cantor offered in print of the application of his set-theoretical ideas to natural science. Although the intended biological applications remained basically undeveloped, he toyed with hypotheses linking his novel theory with the constitution of matter and the ether. Throughout, we shall see that keeping in mind the physical and biological targets that Cantor pursued sheds new light on several results of the crucial period 1882-1885, during which he made his most innovative contributions to set theory. By way of conclusion, section 7 shall come back to the broader themes and offer some reflections on the German intellectual atmosphere in the nineteenth century.

A word of warning is in order. I should make explicit that the following account is by necessity incomplete and tentative. Though I have done my best to collect all the available evidence, that pertaining to the early period around 1870 is scant. It may be possible that new evidence will turn up in letters, e.g., to his family, ${ }^{4}$ but we must take into account that most of Cantor's papers disappeared during World War II. Therefore, it may well happen that no new evidence will emerge, making it impossible to provide further clarification of the topics that we shall discuss.

\section{The insufficiency of Cantor's mathematical motives}

In this section I will argue that the direction of Cantor's work after 1872 cannot be sufficiently explained by taking into account the research agendas of nineteenthcentury mathematicians. This claim is reinforced by the fact that Cantor took only a modest interest in exploiting possible mathematical applications of his new ideas, suggesting his ultimate targets lay elsewhere. We shall make an effort to explain these matters without entering into many technical details of Cantor's mathematics. ${ }^{5}$

Cantor's early work on set theory was motivated by studies in the representation of real functions by means of Fourier series. This was certainly work of great interest by the time it was published, as in 1870 Cantor was able to produce a simplified proof

\footnotetext{
${ }^{3}$ I mean in Cantor 1878 and 1882. See section 6.2 and the final paragraphs of section 3.

${ }^{4}$ Thanks to the kind collaboration of Reinhard Bölling, I have been able to discard the possibility that the letters to Schwarz (kept at the Akademie der Wissenschaften, Berlin) could be of help here.

${ }^{5}$ For detailed presentations of the mathematical development of Cantorian set theory, the reader is referred to specialized literature, particularly Dauben 1979, Meschkowski 1983, Hallett 1984, Purkert and Ilgauds 1987, Ferreirós 1999.
} 
of the theorem that, whenever a real function has a representation by Fourier series, this representation is unique. In 1872 he generalized this uniqueness result by allowing infinitely many points in which either the series is not convergent or it does not coincide with the function, introducing in order to do so (and specify the conditions to be met by the set $P$ of "exceptional" points) the concept of the derived sets $\mathrm{P}^{\prime}, \mathrm{P}^{\prime \prime}, \ldots \mathrm{P}(n) \ldots$ of the point-set $P$. Derived sets became a very important tool, during the following years, in the realm of the theory of real functions and integration. All of this offers a perfect example of the kind of development that does not call for further explanation, apart from the intra-mathematical motives at work.

However, this very early period up to 1872 was exceptional, being the only time during which Cantor's research program was clearly determined by research goals of general interest. In 1874, Cantor published his path-breaking paper proving that the algebraic numbers are denumerable (can be put in one-to-one correspondence with the natural numbers), while the set of real numbers is non-denumerable. Some historians have claimed that this research can be understood as a more-or-less natural outgrowth of the previous work on real functions (see Dauben 1979). Cantor had shown in 1872 that some infinite sets of points are irrelevant to the question of representability of real functions. He might well have been intrigued by this and led to ask why, from the point of view of analysis, even an infinity of points can be regarded, as it were, as non-existent. Such infinities (sets of exceptional points $P$ of the kind he considered in 1872) turn out to be denumerable sets, while the real line $\mathbb{R}$ (as also the rest $\mathbb{R}-P$ ) is non-denumerable.

That is certainly a plausible account, and as such it cannot be discarded. But the fact is that Cantor never made this connection explicitly - it has only been offered by historians in retrospect as a plausible reconstruction. If we turn to historical facts, we find that Cantor saw connections between his famous result of 1874 and the nature of the continuum: "so I found the clear difference between a so-called continuum and a collection of the kind of the totality of real algebraic numbers," he wrote then (Cantor 1932, 116). ${ }^{6}$ It should also be noted that already before 1869, that is before he had done any work on Fourier series, Cantor gave a proof that the set of rational numbers is denumerable at Weierstrass' seminar in Berlin. ${ }^{7}$ This suggests that from a very early period he was interested in "the labyrinth of infinity and the continuum," as Leibniz called it. We might just as well account for his research of 1874 in terms of Cantor's interest in the philosophy of Spinoza (see $\S 5$ ). At this point, I just mention this possibility by way of contrast, in order to underscore the arbitrariness of preferring the first account merely because it is "purely mathematical."

Cantor continued to be extremely interested in abstract questions concerning the cardinalities of point-sets. (Point-sets $P$ and $Q$ are said to be "of the same cardinality"

\footnotetext{
${ }^{6}$ Interestingly, the sentence was introduced in spite of Weierstrass' contrary warnings (Ferreirós 1999, 183-84).

${ }^{7}$ See Fraenkel 1930, 199, based on documents that were lost in WWII. The point is reinforced by recollections of Schoenflies and Mittag-Leffler (see Bölling 1997, 67).
} 
if and only if there exists a one-to-one correspondence between them - intuitively, if they have "just as many" elements - the set of natural numbers and the set of rational numbers have the same cardinality, while the set of real numbers has a larger cardinality.) Already in 1874, Cantor posed the question to Dedekind whether a squared surface and a line segment may have the same or different cardinalities. When he finally obtained a proof that the cardinalities are actually the same, and published it in 1878 , he established an explicit connection between this research and the so-called "space problem" (Cantor 1878, 120-21).

The space problem emerged from studies of non-Euclidean geometries. At stake was a mathematical question of utmost importance for physical theory. The investigations of Riemann, Helmholtz, and others, "on the hypotheses upon which geometry is founded," tried to clarify the exact scope of available options for mathematical modeling of physical space. Cantor had proven that the real line $\mathbb{R}$ has the same cardinality as two-dimensional space $\mathbb{R}^{2}$ (or for that matter $\mathbb{R}^{n}$ ), and this bore consequences for the abstract characterization of the dimension of a space. Cantor would come back to this problem-area a few years later (1882), proving that there exist discontinuous spaces $S$ such that there are continuous paths between any two points in $S$. Thus, "the mere fact of continuous motion" cannot be used to establish conclusively "the complete continuity of the three-dimensional concept of space employed to explain the phenomena of motion" (Cantor 1882, 157).

While Cantor thought about some of the most abstract features of the space problem in the foundations of physics, from 1878 to 1882 mathematicians such as du Bois-Reymond, Dini, and Harnack were taking up his earlier line of research on real functions. In the process they helped create a modern theory of real functions, producing work that was immediately appreciated by the mathematical community. Although Cantor was anxious to see his own work published and acknowledged, apparently he had little time to develop its implications for mainstream mathematics, a task he almost always left to others. ${ }^{8}$ As a result, his work was frequently ignored or regarded as irrelevant by the mathematical community. This applies above all to his results in general set theory, not to the theory of point-sets (see $\S 2$ ).

An interesting case in point is that of the above-mentioned theorem, that there exist discontinuous spaces with continuous paths. Cantor's result did not stimulate further research by mathematicians interested in the foundations of geometry, but it led Emile Borel to a new result in function theory, establishing a generalized form of analytic continuation between two given functions on the complex plane (see Grattan-Guinness 1980, chap. 4, sect. 6, written by T. W. Hawkins). Although this, taken in isolation, proves nothing, it is nevertheless a typical example of the kind of situation we find with Cantor's work. He was developing results along a line of

\footnotetext{
${ }^{8}$ Two exceptions are results that were important in the history of integration theory: a theorem of 1883 presented with explicit reference to the work of du Bois-Reymond and Harnack (Cantor 1932, 160-61), and some results of 1884 (ibid., 229-36). But see $\S 6.2$ adjacent to the reference to footnote 66.
} 
research that had its own, peculiar, and probably speculative motives, and he failed to develop applications to mainstream mathematical topics. Such applications were found by younger mathematicians who were deeply involved in mainstream research but also became aware of the potentiality of Cantor's work.

A most important outcome of the 1878 work on the cardinality of $\mathbb{R}^{n}$ was the Continuum Hypothesis. All of the subsets of $\mathbb{R}$ and $\mathbb{R}^{n}$ that Cantor was able to consider had turned out either to be denumerable (the rational numbers, the algebraic numbers, the sets of "exceptional" points in his early work) or to have the same cardinality as $\mathbb{R}$ (the irrational numbers, spaces of two, three, or even denumerably many dimensions). Cantor was thus led to conjecture that any infinite subset of a continuum fell under one of the two kinds, which in turn meant that the cardinality of $\mathbb{R}$ is the next greater cardinality after that of denumerable sets. This is the "Continuum Hypothesis" in its simplest form, a purely mathematical question that had never been posed before. It became the veritable center of Cantor's research thereafter, the North Star that guided his exploration of the labyrinthine universe of transfinite sets.

The Continuum Hypothesis $(\mathrm{CH})$ stands out as the quintessential example of the kind of new mathematical question Cantor was able to pose. In line with what we said above regarding his 1874 non-denumerability theorem, we may consider two main scenarios to account for his interest in this problem. As a pure mathematician, Cantor may have been led to $\mathrm{CH}$ because of his interest in deep, fundamental questions connected with analysis and the theory of real functions. On the other hand, he might have been led to conjecture $\mathrm{CH}$ because he was motivated by speculative philosophicoscientific questions. As historians, we should try to decide between these two scenarios by paying careful attention to Cantor's own declarations. The first paper in which Cantor opened his heart and expressed his research intentions is the all-important Grundlagen (1883), discussed in $\S 3$.

While trying to prove the Continuum Hypothesis, Cantor was led to develop a number of important new concepts in the topology of point-sets, to introduce (in the Grundlagen) the radically new transfinite numbers, and to prove several fundamental results like the Cantor-Bendixson theorem. The latter offers a new example of the relation, sketched above, between Cantor's results and their mainstream applications. Mittag-Leffler was able to exploit (a certain part of) the Cantor-Bendixson theorem to construct analytic functions with prescribed isolated poles, thereby generalizing a famous theorem of Weierstrass. The leader of the Berlin mathematical school was impressed, saying that the main problem of the theory of analytic functions, which previously seemed a matter for the future, had now found its most general solution (for further details see, e.g., Ferreirós 1999, 206). Cantor, however, essentially bypassed these kinds of applications of set theory - at the very least he had no time for them and left to third parties the task of developing them. This suggests that his motivation lay outside analysis. His main concern seems to have been with abstract questions regarding the nature of the continuum, and with the $\mathrm{CH}$. 
We might go on reviewing the mathematical motivations (or lack thereof) in Cantor's research, but the foregoing seems sufficient for our purposes. To summarize, his innovative research can hardly be understood from the standpoint of mainstream problems in contemporary mathematics. To the extent that he pursued purely mathematical problems, these were novel ones that he had posed himself. And, although it frequently turned out that his results (very especially those in point-set theory) had very interesting applications in analysis, Cantor's attention seems to have been elsewhere. To be more precise, one can differentiate rather sharply between Cantor's general set theory, received (as we shall see) in a very skeptical mood, and his results in point-set theory, received rather quickly. Even so, his results in point-set theory did not originate in mainstream mathematical problems.

If one now asks where exactly Cantor's attention was directed, and why he was led to pose the new problems, a preliminary answer is - because of an abstract interest in the nature of the continuum (see $\S 6.1$ ) and its connections with scientific theory (e.g., the cases of the space problem, the problem of dimension, and the issue of continuous motion in discontinuous spaces, all of them related to physics). As we shall see, there is plenty of evidence to suggest that we should consider a broader field of questions, which we may label the "organic explanation" of natural phenomena, embedding and giving sense to these focal points of Cantor's research program.

Two further points should be stressed before proceeding to the next section. To say that key focal motives of Cantor's research were extra-mathematical, is not to imply that his work was indifferent to purely mathematical results and methods. The real situation is exactly the opposite. Similarly, my analysis of the extra-mathematical goals Cantor set for himself does not in the least affect the question of the mathematical quality of his production. All his papers reveal a very high standard of rigor when judged from a mathematical standpoint, which to a large extent reflects the high quality of the education he received at Berlin. In a letter of April 1870, Schwarz expressed his happiness to see Cantor bring a new triumph to "the Berlin mathematical school, to which we both belong." He stressed the solidity of their education, emphasizing how the painful care with which they had learned to treat mathematical proofs gave them enormous superiority over "the mathematical 'romantics' and 'poets'." Ironically, without this kind of education, the romantic Cantor would never have been able to produce his mathematical poetry in such an impressive and lasting form.

\section{Matters of reception}

Reception studies offer a useful indicator of whether an author's work was in line with contemporary research and oriented by mainstream problems. As we shall see in this

\footnotetext{
${ }^{9}$ Schwarz to Cantor, 1 April 1870 (Meschkowski 1983, 240).
} 
section, the reception of Cantor's work among the leading European mathematicians reinforces our overall interpretation.

A high point in the reception of Cantorian set theory came around 1883, the year he published the Grundlagen, but also a French translation of his most important papers to appear in Acta Mathematica. At this time, Mittag-Leffler wrote him as follows:

Apart from Weierstrass and perhaps Kronecker, who nevertheless has little interest for these questions, and who besides will scarcely share your viewpoints - there is in Germany no mathematician with the fine sense for difficult mathematical investigations, required for a correct appreciation of your work. Did not Felix Klein say to me just a few years ago which of course should remain between ourselves - that he could not see what the use was of all that. Among Weierstrass's students in Germany, perhaps Schottky is the only one who may have some understanding for your work. And I can imagine very lively how our common friend Schwarz will curse at you [über Sie schimpfen]. ${ }^{10}$

Mittag-Leffler may have been interested, for the sake of his journal, in casting doubt about Klein (then editor of Mathematische Annalen) in Cantor's mind, but still his perception of the situation in Germany was quite accurate. In reply, Cantor stated that he agreed completely and remarked: "if I did not know that apart from the Germans there are also other mathematicians in the world, I would have published absolutely nothing on mathematics for the last twelve years."11

Leopold Kronecker's harsh criticism of Cantor's work is, of course, very well known. Kronecker was an extremely influential mathematician, deeply concerned about foundational and methodological questions in mathematics. Cantor himself reported to Mittag-Leffler:

Kronecker, who visited me by the beginning of July, explained to me with the most amicable laughs that he had corresponded much with Hermite apropos my last work [Grundlagen], to show him that it was all nothing but "humbug." As I have grown accustomed to such statements, I did not get angry with that comment, but had my bit of fun. Of the suprafinite numbers he said, to my amusement, that "only in heaven he hoped to come to the point of being able to understand them." But, as funny as it may be for me, the thing is no less serious, insofar as a large number of mathematicians have their judgements determined by the opinions of Kronecker, who, as we know very well, throws them around with the greatest emphasis and sans géne. ${ }^{12}$

In the coming months, Cantor would grow more and more obsessed with the fierce criticism and the "intrigues" of Kronecker, Schwarz, and their followers.

\footnotetext{
${ }^{10}$ Mittag-Leffler to Cantor, 10 January 1883 (Cantor 1991, 242).

${ }^{11}$ Cantor to Mittag-Leffler, 14 January 1883 (Cantor 1991, 110) (emphasis in the original).

${ }^{12}$ Cantor to Mittag-Leffler, 9 September 1883 (Cantor 1991, 127) (emphasis in the original).
} 
The situation with Carl Weierstrass is more subtle and therefore of greater interest, but I believe it confirms the lack of interest in Cantor's dearest results. Weierstrass was rather the opposite of his former friend Kronecker - a shy man, very moderate in his declarations. This must be taken into account when considering his reaction to Cantor's work, but it is hard to avoid the impression that he was reluctant most of the time. In 1874 , confronted with the proof that $\mathbb{R}$ is non-denumerable, he warned Cantor against jumping to the conclusion that there are "essential differences" between infinite sets. ${ }^{13}$ In November 1882, Cantor informed him about the new idea of the transfinite numbers, but he did not answer. Then, in February 1883, Cantor visited him, and this is what he found:

He has not expressed scruples of any kind against my introduction of suprafinite numbers, it seemed rather to interest him; but he showed particular interest in sections $\S 9$ and $\S 10$, especially in my conception of the continuum. ${ }^{14}$

Section 9 of the Grundlagen was a discussion of definitions of the real numbers given by Weierstrass, Dedekind, and Cantor; Section 10 a pioneering definition of the continuum.

Weierstrass thus showed an interest in those parts of Cantor's work that promised to be relevant for analysis, i.e., those pertaining to the topology of point-sets. We may safely conjecture that he only expressed a polite interest in all the rest, including transfinite sets, their cardinalities, and the theory of the transfinite numbers. In 1885 Weierstrass was interested in generalizing the concept of the integral, and wrote to Schwarz that for that purpose "the recent investigations of Cantor (not those related to the transfinite numbers) have done me essential service." 15 The abstract turn of Cantor's research, his devotion to highly speculative questions about the infinite and the continuum, like the Continuum Hypothesis, seem to have lacked real interest for Weierstrass.

In the letter quoted above, Mittag-Leffler expressed great expectations about the reactions among French mathematicians, in particular Charles Hermite and his students. But after revising the translations of Cantor's papers, early in 1883, Hermite was not really enthusiastic:

The impression that Cantor's memoirs produce on us is disastrous. Reading them seems to us a complete torture.... Even acknowledging that he has opened a new field of research, none of us is tempted to follow him. It has been impossible for us to find,

\footnotetext{
${ }^{13}$ Cantor to Dedekind, 27 December 1873 (Dugac 1976, 226). Weierstrass was interested in the proof that all algebraic numbers can be put in the form of a denumerable sequence.

${ }^{14}$ Cantor to Mittag-Leffler, February 1883 (Cantor 1991, 112). See also ibid., 95-110, for other letters that establish the fact that Weierstrass had not reacted before.

15 Weierstrass to Schwarz, May 1885 (Dugac 1973, 141). He probably meant notions in point-set topology and the "outer content" of point-sets, a forerunner of measure theory that Cantor had recently introduced.
} 
among the results that can be understood, a single one having a real and present interest. The correspondence between points in the line and in the surface leaves us completely indifferent, and we think that this remark, insofar as nobody has inferred anything from it, arises from such arbitrary methods that the author would have done better retaining it and waiting. ${ }^{16}$

As Hermite explained, Picard had read the Grundlagen without stopping to curse at the author. Among Hermite's students only Henri Poincaré shared Mittag-Leffler's judgment that Cantor's ideas were important, "even though he judges [them] to be very premature in the present state of analysis." In Poincaré's opinion, the Grundlagen was a "beautiful memoir," but French readers would be "absolutely refractory" to Cantor's mathematical and philosophical investigations. ${ }^{17}$ Today we read his work in general set theory with the conviction that it is a capital contribution to mathematical thought and a work of genius. Hermite and Poincaré remind us of the feelings that unprejudiced readers could have at the time, approaching Cantor's work with no such preconception.

Even Richard Dedekind, who among German mathematicians had always been the most open to Cantor's innovations, failed to react at all when confronted with the transfinite ordinal numbers in November 1882. Cantor sent him a detailed account of the great novelty, described as "the most remarkable and unexpected results" in set theory and the theory of numbers, which it had "pleased Almighty God" to let him attain. But Dedekind left this letter unanswered, and with this their episodic correspondence of 1872-1882 came to an end. ${ }^{18}$ This came shortly after Dedekind's refusal to accept a position at Halle, and it must have contributed to increase Cantor's feelings of isolation. Years later, reflecting back on the period around 1890, Hilbert expressed the view that he and Minkowski had been the very first German mathematicians to show a deep interest in transfinite numbers.

One aspect of this whole state of affairs is somewhat surprising. As we remarked, Cantor left to others the task of exploiting the implications of his novel ideas for mainstream mathematical topics. Had he been of a purely contemplative nature, with no particular interest in career-making and influence, we would have a natural explanation for that. But this was not the case. There is ample evidence that Cantor suffered in Halle, and felt he deserved to become a professor at one of the foremost German universities, either Berlin or Göttingen. ${ }^{19}$ We may certainly agree with his judgment that, because of his deep contributions, Cantor deserved such a position better than his contemporaries, but it would be ahistorical to consider the matter without taking

\footnotetext{
16 Translation taken from Moore 1989, 96 (emphasis in the original).

${ }^{17}$ Hermite and Poincaré to Mittag-Leffler, letters January-March 1883 (Dugac 1984, 69-71) (emphasis in the original).

${ }^{18}$ Only in 1899 did they resume corresponding for a short time (see Ferreirós 1993). As regards the reasons for Dedekind's discourtesy, see also Grattan-Guinness 1971, Dugac 1976, Purkert and Ilgauds 1987.

${ }^{19}$ See, e.g., Cantor to Hermite, January 1894 (Meschkowski 1965, 514-15). More generally, see Purkert and Ilgauds 1987, 53-55, 76, 163. Cf. also Grattan-Guinness 1971, Dauben 1979.
} 
into account how his work was perceived by the community to which he belonged. Cantor's aspirations to a chair at one of the two leading universities ran against the views of the mandarins of German mathematics, who were as skeptical as Hermite (if not more so) regarding his work. ${ }^{20}$ Cantor simply lacked mainstream contributions, and a good deal of his production had little relevance for his colleagues. As late as 1898, Emile Borel would say that Camille Jordan "rehabilitated" set theory by showing that it was "a useful branch of mathematics ... through his researches on the measure of areas and sets, on integration." 21

Cantor could easily have corrected this perception, and built a much more successful career, had he concentrated his research (for a few years at least) upon the implications of his new ideas in the realm of function theory and integration theory. One can hardly doubt that he had all the abilities necessary to do brilliant work in those realms, but he seems to have lacked the interest to apply set theory (even point-set theory) to modern analysis. This was an important trait of his turn of mind and personality. All we have said reinforces the impression that Cantor's research was not guided by key intra-mathematical questions, originating in the mathematical research programs of his time. What, then, were the motives behind his development of set theory?

\section{Natural philosophy in the Grundlagen}

Cantor's Grundlagen is unique in the history of modern mathematics, an astonishing blend of mathematical ideas and philosophical argument that opened the way to a full-blooded development of abstract set theory. It was a long paper, published in the Mathematische Annalen, that Cantor regarded as extremely important, for which reason he also published it separately, under the title above and with the explicit subtitle $A$ mathematico-philosophical attempt in the theory of the infinite. ${ }^{22}$ I have already mentioned that this work marked a veritable turning point in Cantor's career. Up to then, his research was limited to the realm of point-set theory, studying subsets of $\mathbb{R}^{n}$ from the combined viewpoints of cardinality and topology. The main topic of the Grundlagen was the introduction of the transfinite ordinal numbers, which led Cantor to the study of well-ordered sets. With these new ideas, he was able to jump to the more abstract viewpoint of "transfinite" set theory. The new standpoint was clearly expressed in a paper written the following year, ${ }^{23}$ and would be developed fully in his last two articles, published in 1895 and 1897.

\footnotetext{
${ }^{20}$ One may conjecture that Cantor's personality had its importance too.

${ }^{21}$ Quoted in Hawkins 1975, 96. The reference is to Jordan's Cours d'analyse (Paris, Gauthier-Villars, 1893). Borel here betrays some ignorance of relevant work done by Harnack, du Bois-Reymond, and others in the 1880s.

${ }^{22}$ It should be noticed that this kind of mixture (in particular the inclusion of many historical and philosophical remarks and the narrative style) was very far from the usual standard in mathematical papers at the time.

${ }^{23}$ Which however remained unpublished and lost until its rediscovery by Grattan-Guinness (see GrattanGuinness 1970).
} 
In order to justify the introduction of the transfinite ordinals, Cantor felt obliged to confront age-old prejudices against actual infinity. This led him to open his heart and provide the readers with a surprising new perspective of his speculative mind. It became apparent that, for him, the mathematical questions of set theory were deeply intertwined with philosophical problems (including matters of theology) and with speculations on Nature. In February 1883 he wrote to Klein, the editor of Mathematische Annalen, asking him to publish "the whole work":

I can assure you that the work is thoroughly mathematical, even if it contains few formulas and I had to discuss many philosophical [points] pertaining to the matter. Unfortunately things have become so intertwined in my mind, that it would be very difficult for me to separate what is purely mathematical in the work from the rest. ${ }^{24}$

The Grundlagen was written between October 1882 and January 1883, falling squarely in what may be called Cantor's golden years, and it is arguably his most original and noteworthy contribution of the period. Zermelo, the expert in set theory and editor of Cantor's papers, wrote that in the period 1879 to 1884 Cantor produced the "quintessence" of his original set-theoretical work. ${ }^{25}$

Grundlagen consists of 13 sections and 12 very relevant endnotes. Of the main sections, eight are essentially mathematical, five are mainly philosophical (sections 48 ), and one deals with the definition of the continuum. ${ }^{26}$ It is in the philosophical sections and the endnotes, that one finds explicit references to the extra-mathematical motivations behind Cantor's work. Particularly noteworthy is section 8, in which Cantor defends the methodology of modern mathematics against the finitistic, constructivistic critique of Kronecker (without naming him). It was the first time that an explicit defense of the viewpoint adopted by Riemann, Dedekind, and Cantor himself, appeared in print. And the arguments given here anticipate in a very explicit way Hilbert's famous idea that the logical consistency of mathematical theories (axiom systems) is ultimately the only meaningful criterion for establishing mathematical existence.

Most noteworthy for our present purposes is that with Cantor these ideas come out dressed in metaphysical language, linked by the author with the philosophical systems of Plato, Spinoza, and Leibniz. Cantor distinguishes the "intrasubjective or immanent reality" of an idea from its "transsubjective or transient reality." An idea possesses immanent reality when it is well-defined and logically consistent, standing in orderly relation to previously existing concepts. The question of transient reality is the metaphysical problem of the connection between the idea and "events and relationships

\footnotetext{
${ }^{24}$ Cantor to Klein, 7 February 1883 (Cantor 1991, 113).

${ }^{25}$ See the editorial remarks in Cantor 1932, 246 (and also Fraenkel's words, ibid., 460-461). Note that the Grundlagen was finished more than one year before Cantor's mental crisis in the spring of 1884.

${ }^{26}$ The reason for putting section 10 in a category of its own will be apparent later (see section 6.1).
} 
in the external world," i.e., "in physical and mental Nature." In Cantor's own words:

Because of the thoroughly realistic but, at the same time, no less idealistic foundation of my point of view, I have no doubt that these two sorts of reality always occur together in the sense that a concept designated in the first respect as existent always also possesses in certain, even infinitely many, ways a transient reality. ${ }^{27} \ldots$ This linking of both realities has its true foundation in the unity of the all to which we ourselves belong. - The mention of this link here has only one purpose: that of enabling one to derive from it a result which seems to me of very great importance for mathematics, namely, that mathematics, in the development of its ideas, has only to take account of the immanent reality of its concepts and has absolutely no obligation to examine their transient reality. (Cantor 1883, 181-82; emphasis in the original)

It is certainly noteworthy that Cantor felt compelled to make this explicit confession of philosophical faith in order to justify his mathematical methods. The joint endorsement of realism and idealism; the emphasis upon the "unity of the all"; the linkage to Plato, Spinoza, and Leibniz - all this suggests an image of Cantor the philosopher as a Romantic thinker in the grand style of the professors whose lectures he heard at Berlin and Göttingen (see $\S 5$ ).

In a key passage in the Grundlagen, towards the end of section 5, Cantor discusses traditional conceptions of the infinite among philosophers. In that context, he notes that the set-theoretical methods that he has introduced can contribute toward solving the chief difficulties in the systems of Spinoza and Leibniz. These difficulties, he says, have led to Kantian critical philosophy, but this doctrine and its successors

have not, it seems to me, yielded an adequate substitute for the hindered development of the theories of Spinoza and Leibniz. For alongside of (or in place of) the mechanical explanation of Nature (which inside its proper domain has all the aids and advantages of mathematical analysis available, but whose one-sidedness and insufficiency have been strikingly exposed by Kant) there has until now not been even the start of an organic explanation of Nature that would attempt to go further and that would be armed with the same mathematical rigour; this organic explanation can, I believe, be initiated only by taking up afresh and continuing the works and endeavours of those thinkers. (Ibid., 177; emphasis in the original)

In endnote 6, Cantor went so far as to say that Kant's criticism grew out of seventeenthand eighteenth-century empiricism, sensualism, and scepticism. He denied that sensory experience or the Kantian forms of intuition may furnish us with any secure knowledge,

\footnotetext{
27 To this, Cantor appends endnote 6: "This conviction agrees essentially both with the principles of the Platonic system and with an essential tendency of the Spinozistic system. . . The same epistemological principle can also be found in the philosophy of Leibniz...." (Cantor 1883, 206-07).
} 
and endorsed the Platonic doctrine that our concepts and ideas are merely awakened and brought to consciousness by experience.

In several places in the Grundlagen, Cantor repeats the idea that transfinite sets and "all of the different, successive, ascending" transfinite cardinalities occur in physical and mental Nature, and that he regards as his task "to pursue [the transfinite numbers] and establish them wherever they occur in Nature" (Cantor 1883, 199, § 12; and 205, n.2). As we shall see, this topic would remain at the center of his interests, and he went on to attempt some concrete proposals along these lines. In work of 1887 he would say that the task of determining all of the cardinalities which can be found "in all of Nature" is "one of the most important problems of set theory." $(!)^{28}$

The statement in the Grundlagen that Cantor was pursuing a new mathematics that could initiate the development of "an organic explanation of Nature" is perfectly consistent with his confession to Mittag-Leffler in the letter of September 1884, quoted at the start. He thus hoped to go beyond positivistic descriptions of Nature, in the style of the well-known physicist Kirchhoff, transcending them by the instillation of "the fresh breeze of free mathematical thought" into natural science. He hoped thereby to attain "the power of explaining and fathoming [der Ergründung von] natural phenomena" (ibid., 183, $\S 8$; emphasis in the original).

Readers of the present paper might accept the evidence I have given and the idea that Cantor was somehow motivated by speculations on natural philosophy, while simultaneously being inclined to deny that all this could have played any noticeable role in directing his actual research. To counter this way of thinking, we might recall the previous example $(\S 1)$ of his 1882 result on the possibility of continuous motion through discontinuous spaces. While Cantor failed to develop its possible implications for function theory, he stressed the link between this result and speculations on "the constitution of the real world," including the possibility of a "modified mechanics" (Cantor 1882, 156-57). This was actually the very first emergence of natural philosophy in his mathematical papers, if we except his reference to the Riemann-Helmholtz space problem in a previous paper (Cantor 1878, 120-22). But there are even better examples.

In a letter of October 1883 to the psychologist and philosopher Wilhelm Wundt, Cantor tried to convince him that the transfinite ordinals and the alephs are not merely abstract possibilities, "logical postulates," but can actually be regarded as "obtained through abstraction from reality" just like the natural numbers. To do so and show their applicability to Nature, Cantor mentioned by way of example the following result:

If we consider the collection of all organic cells at a given time in our cosmos, which expands itself infinitely in all directions, it is certain that this collection consists of infinitely

${ }^{28}$ Cantor $1887 / 88,387$; the text comes from a letter of 1884 . See also references to the transfinite as realized in "the world of creatures" (ibid., 378). 
many individuals; one can therefore state the question regarding the "power" [cardinality, aleph] of this set, and I can prove rigorously that the power in question is the first $\left[\aleph_{0}\right]$, i.e., not a greater one. ${ }^{29}$

The editors of his Briefe express the opinion that Cantor never proved this, and that only his great desire to convince Wundt led him to present a mere hypothesis as a proven result. The truth is, however, that Cantor had published his proof one year before, in the same paper that contains the theorem mentioned in the previous paragraph. Cells can be regarded as three-dimensional continuous subdomains of Euclidean space, separated from each other so that they can at most touch each other along their borders; and Cantor proved that a set of infinitely many subdomains, having such properties, must be denumerable, i.e., of power $\aleph_{0}$ (Cantor 1882, 153-54). (Of course, Cantor could only prove his assumption that there are infinitely many cells by a metaphysical argument in the style of Leibniz and Spinoza.) ${ }^{30}$

In the paper of 1882, Cantor did not indicate the possibility of this application to the organic view of Nature, which one can find only in the letter to Wundt. He was content with presenting the result as an interesting application of the concept of denumerability within the field of geometry. (As a matter of fact, the theorem is formulated and proven for $n$-dimensional subdomains of $n$-dimensional spaces, which is in the spirit of Riemann's geometrical work and involves no special technical difficulty.) However, it is intriguing that Cantor may have been led to his "geometrical" theorem by speculations on natural philosophy. All of this throws new light, too, on the previously obscure indications Cantor made that set theory was not limited to mathematics but applied also to other "conceptual spheres" (Cantor 1882, 150, 152). ${ }^{31}$

Even if the above seems quite convincing and suggests new avenues for the analysis of Cantor's development of transfinite set theory, a crucial problem remains. Are we entitled to assume that he was motivated by such views and hopes as early as 1870 ?

\section{Cantor's philosophical and religious views around $\mathbf{1 8 7 0}$}

The deep interest in philosophy that we find in Cantor was not at all uncommon at the time. He was by no means an exception in this, though he was exceptional in combining to such an extent philosophy and mathematics in his publications. To give but a few examples of first-rate mathematicians, Riemann may even be considered

\footnotetext{
${ }^{29}$ Cantor to Wundt, 16 October 1883 (Cantor 1991, 142). $\aleph_{0}$ is the cardinality of denumerable sets in Cantor's 1895 notation.

${ }^{30}$ Based on the perfection of God's creation; see Cantor 1887/88, 396, 406, but especially 399-400.

${ }^{31}$ See also the reference to "Logik und Erkenntnislehre" in 1883, 181, and the emphatic "sehr viel umfassenden" in endnote 1 of this same paper $(1883,204)$.
} 
a philosopher, he was very serious both in his study of the philosophical writings of Herbart and several others, and in his original developments. Among Cantor's professors at Berlin, Kummer was steeped in Hegelianism, to such an extent that his student and close friend Kronecker said he was "through and through a Hegelian"; and Kronecker himself reveals detailed knowledge of philosophy. ${ }^{32}$

Through his philosophy professors, Cantor established contact with the ideas of Spinoza and Leibniz. As a good student and serious apprentice philosopher, he did not remain content with knowing their views second hand - instead, he devoted a good part of his time to reading directly the seventeenth-century masters. This, and his creative turn of mind, allowed him to develop an original position and synthesis, which was also based on detailed knowledge of contemporary scientists (see $\S 6$ ). Many traits of Cantor's views were characteristic of late Romanticism, including the deep conviction that a true scientific system will be perfectly consistent with metaphysical viewpoints, and thereby admit of a teleological religious interpretation.

\section{1.}

In his student years, 1863 to 1867, Cantor showed explicit interest in philosophy and physics, taking advantage of the Lernfreiheit of the German university system. His engagement with philosophy seems to have been especially intense, in particular with the rationalistic system of the seventeenth-century philosopher Baruch Spinoza. We know that in the oral examination for his $\mathrm{Ph}$.D. he was questioned in number theory by Kummer, in algebra and function theory by Weierstrass, in physics by Dove, in Spinoza's philosophy by Trendelenburg (more on this philosopher below). One year later, Cantor passed the Prussian examination for secondary school teaching. In the official report there is a lengthy commentary on a piece about Spinoza that he presented for the occasion:

The philosophical work of the candidate, which attempted to answer the question: What does Spinoza understand by geometrical method in his Ethics, and how should his application of it be judged? is wrong in its general plan; but it gives proof that its author has tried to deal with the first part of the question in Spinoza's sense and with all possible precision. In the oral examination the candidate showed more a practical than a theoretical familiarity with the logical principles, his answers were often not precise enough, his definitions not infrequently insufficient. Besides a general knowledge of the history of philosophy, he showed detailed acquaintance with the ethics of Spinoza. (Purkert and Ilgauds 1987, appendix 1, 183-85; emphasis in the original)

\footnotetext{
${ }^{32}$ Concerning Riemann, see Scholz 1982 and 2001, and Ferreirós 1996. Kronecker's words are taken from Boniface and Schappacher 2001, 223. Kummer's speeches before the Berlin Akademie der Wissenschaften (in his Collected papers) are particularly instructive. One may also mention that a first-rate German philosopher like Husserl made a thorough study of mathematics (under Weierstrass) and physics at Berlin.
} 
Even later, in the winter of $1871 / 72$, while already at Halle as a Privatdozent and working on Fourier series ( $\S 1$ ), he started to write a commentary on part I, "On God," of Spinoza's Ethica more geometrico demonstrata. ${ }^{33}$

All of this confirms that Cantor was strongly attracted to Spinozism, and the later testimony of the Grundlagen merely reaffirms the point. The interesting aspect of this is that infinity plays a key role in Spinoza's metaphysical system. The rationalistic philosopher attempted a strict proof that there is only one substance in the world, which he calls "God or Nature," and which is absolutely infinite. Extension (i.e., matter) and Thought are just two "attributes" of the one and only substance; finite beings are "modes" of these attributes. The finite - our bodies and minds included is just an expression of the absolutely infinite substance; all beings are modifications of "Natura naturata." 34 Spinoza's ideas have given rise to a never-ending discussion on whether he was a pantheist, or perhaps even a materialist. Cantor strived to interpret his philosophy in such a way as to avoid both "dangers."

Quite obviously, the influence of Spinoza's philosophy can help explain Cantor's early interest in further mathematical determination of the infinite. One impact of these philosophical studies, and of his later reading of theology, is well known: Cantor's thinking about infinity was partially shaped by the idea of God as the absolutely infinite, which he always kept in mind and took into account. He regarded the transfinite realm as lying between the finite and the Absolute, and the relation between transfinite and Absolute as analogous to that between the finite and infinity. These ideas had very explicit and concrete effects when Cantor found the paradoxes or antinomies of set theory around 1896 - they prepared him to accept the antinomies as natural results, in strong contrast to most of his contemporaries. ${ }^{35}$

As we have seen, by the time of Grundlagen Cantor had become deeply interested in the philosophy of Leibniz and Plato, too. Putting these interests in context, one can say that a good number of Romantic philosophers were influenced by Spinoza and Leibniz, so that Cantor's choices were in no way idiosyncratic. Spinoza's philosophy highly influenced Schelling and Hegel, though of course their views incorporate deep novelties such as the insistence on historical evolution through phases by dialectical changes. Hegel and Schelling were generally regarded as pantheists, while Cantor consistently tried to avoid this "temptation," to which end he found guidance in the writings of theologians. But, whatever the differences, the revival of speculative rationalism seems to have been one of the lasting effects of the idealistic age, even after

\footnotetext{
${ }^{33}$ See Purkert and Ilgauds 1987, 31. The draft interrupts after just 7 pages.

${ }^{34}$ To be distinguished from the absolutely infinite "Natura naturans." This distinction is Spinoza's attempt to preserve something of the traditional distinction between the Creator ( $N$. naturans) and its creation ( $N$. naturata). 35 The role of the Absolute is, once again, explicit in the Grundlagen. For detailed analysis of this whole circle of questions, see Purkert 1986 (also in Purkert and Ilgauds 1987, 147ff.) and Jané 1995, although I do not share Purkert's belief that Cantor was aware of the antinomies (which must be precise arguments, not just a vague intuition) already in 1883 .
} 
the fall of Absolute idealism, and in this regard Cantor emerges as a typical representative of late Romanticism.

\section{2 .}

Although the broad context of Cantor's philosophico-scientific concerns will be examined further in sections 5 and 6 , it will be clarifying at this point to consider some characteristic traits of the philosophical tendencies represented by his philosophy professors, and compare them with Cantor's own views. Needless to say, the intellectual context was much broader, and one may well assume that Cantor's interests emerged from many other sources, from conversations, reading, scattered lectures, and the like. But it is nonetheless quite interesting to realize that the philosophy lectures he attended at Berlin and Göttingen from 1863 to 1866 are very likely to have displayed before him many of the scientific and philosophical themes that would become his concern. At Berlin, Cantor took several courses in philosophy with Adolf Trendelenburg, an important historian of philosophy and political philosopher, very influential in Prussia; ${ }^{36}$ his best-known student was no less a figure than Wilhelm Dilthey. To begin with, Trendelenburg was deeply influenced by Spinoza in his metaphysics and his theistic and ethical views. He is also noted for having advanced an "organic worldview" (organische Weltanschauung) in which he postulated a parallelism of mental and physical phenomena, where both would be dominated by common principles (of "motion" and "finality"). According to him, conscious thought antecedes the blind natural forces and governs them: "according to the organic worldview, the essence of things lies in a creative thought." 37 Trendelenburg thus tried to capture the inner unity of reality and supersede the blind, senseless conceptions of mechanism. Since he conceived of "logic" as a blend of formal logic, psychology, and metaphysics, his logic course is likely to have included a discussion of the "organic worldview."

However, the affinity between this metaphysical worldview and Cantor's attempts should not be overestimated. After all, Trendelenburg did not try to develop a scientific worldview in any detail. If we contrast Trendelenburg's with Schelling's philosophy, a most noteworthy difference is that the former abandoned any hope that philosophy could change scientific thought. This seems to have been his reaction to the clamorous failure of the ambitious programs of Romantic Naturphilosophie, and he even went on to theorize a role for philosophy of science as a post-facto reflection on natural science. What he called the organic worldview "can also be labeled, avoiding the obscure concept of the organic, as a teleological or religious worldview" (Dilthey

\footnotetext{
${ }^{36}$ See Cantor's own "Vita” of 1867 (Cantor 1932, 31). Cantor heard his lectures on "Psychologie," "Geschichte der Philosophie" (WS 1863/64), and "Logik" (SS 1864); see Bölling 1997, 52.

37 This quotation, from his masterwork Naturrecht auf dem Grunde der Ethik, is taken from Dilthey's review of that work (Dilthey [1860] 1972, 383).
} 
[1860] 1972, 384). This organicism simply affirmed the possibility of understanding the world teleologically from God's standpoint.

In the summer of 1866 Cantor was at Göttingen attending the physics lecture course given by Wilhelm Weber (collaborator of Gauss and noteworthy contributor to electromagnetism) and the philosophy course offered by another great figure, Hermann Lotze. ${ }^{38}$ We shall see (next section) that Lotze, a trained physician, was one of the first to defend a strictly mechanistic viewpoint in biology and medicine. But his views were very far from materialism, in fact he developed a philosophical system which tried to reconcile scientific mechanism with a teleological understanding of Nature. This combination was already a key point in the philosophy of Leibniz, who was a very powerful influence upon Lotze. ${ }^{39}$ Indeed, Lotze's philosophy has been called "a Spinozistic modification of Leibnizianism" (Prantl 1894, 290), which is quite noteworthy given Cantor's philosophical preferences. ${ }^{40}$

According to Lotze, mechanism plays a key role in the structure of the world, but its significance is strictly subordinate. All natural phenomena are mechanical, and science must approach them accordingly and study them in a causal, deterministic way. But the mechanism is at the service of some higher thing, which surrounds it and gives it a foundation. ${ }^{41}$ Mechanism and causality are faithful servants in charge of realizing the spiritual ideas of Nature. Lotze thus affirmed that the world has a spiritual essence, lying at the root of the ultimate finality of all things. This spiritual root was, he believed, obviously manifest in our own mental activity (the activity of the soul), and his philosophy sought to harmonize the needs of the soul with the mechanistic methods of science.

Cantor's views were not too akin to Lotze's either. Both stood close to the aims and ideals of precision and explanation of nineteenth-century science, but, as we have seen, Cantor stated in the Grundlagen that mechanism had to be supplemented or even replaced by an organic explanation of natural phenomena. This shows plainly that he did not follow Lotze and others (e.g., Fechner) in their resignation to accept the full triumph of mechanism in the domain of science. In this respect, Cantor would be closer to Schelling (an author he never cites) than to any of his teachers. The difference with Schelling is that Cantor tried to develop organicism with all the conceptual and methodical rigor of mathematics: he scorned "dialectical logic" and tried to penetrate into the matrix notion of the continuum by studying point-sets and the mathematical infinite. He attempted to become a Newton of the organic world, developing the needed mathematical tools and applying them to natural phenomena.

\footnotetext{
${ }^{38}$ See Cantor's own "Vita” of 1867 (Cantor 1932, 31).

${ }^{39}$ In Leibniz's Monadologie $(1714, \S 79)$ one reads: "Souls act according to final causes ... Bodies act according to efficient causes.... And both reigns, that of efficient causes and that of final causes, are harmonic among themselves."

${ }^{40}$ Prantl does not forget to warn readers that such descriptions through short labels are always insufficient and potentially misleading.

${ }^{41}$ And which, in his article on "vital force" (Lotze 1843), he identified with God's wisdom.
} 


\section{3.}

As regards Cantor's religious beliefs, one should mention that his father Georg Woldemar Cantor (ca. 1813-1863) seems to have played a very important part in them. ${ }^{42} \mathrm{He}$ was a rich merchant with a rather many-faceted personality, imbued with characteristic traits of a Romantic sensibility. For instance, as his son was studying at the Gewerbeschule in Darmstadt, he wrote:

Cherish and preserve the love for the sciences just as the sacred fire of the vestals, whose burning lamp was never allowed to go out. The eternal, never to be extinguished lamp of science, burns with an even more sacred fire than was that one. (Cited in Meschkowski $1983,5)^{43}$

When, in May 1862, the young student obtained parental permission to devote himself to mathematics, he replied to the father saying: "my soul, my entire self lives in my profession [Beruf]; what a man wants and can do, to which an unknown, mysterious voice impulses him, that he will carry through" (ibid.). Here we see a very clear expression of Romantic ideals, including the conception of science as a higher calling.

Georg Woldemar belonged to the evangelical church and took an active part in all aspects of his son's education, but particularly in his moral and religious formation (see, e.g., Meschkowski 1983, 1-3; Dauben 1979). On the occasion of Cantor's confirmation, he wrote a letter that the son would keep lifelong, saying:

Now, my dear son! - believe me, your most sincere, true and experienced friend - the solid core, which must live in ourselves, that is a true religious feeling! This makes itself evident to ourselves in a sincere, humble feeling of most thankful veneration for God, from which then a victorious, unshakable confidence in God grows, keeping us throughout our whole life in that calm and hopeful contact with our celestial Father. (Meschkowski 1983, 3; emphasis in the original)

Apparently, these views penetrated deeply into Cantor's conscience and way of living, and they never abandoned him. His theological convictions may have changed along his life, but the basic feelings that his father was so concerned to seed into his mind remained fixed.

In Cantor's mind, mathematics, metaphysics, and theology stood in indissoluble relations. ${ }^{44}$ In January 1894 he told the great mathematician Hermite that metaphysics and theology had taken up "his soul" so much, that he had relatively little time for

\footnotetext{
42 The topic of Cantor's religion has been very well studied by Meschkowski (1983) and Dauben (1979).

43 The metaphor of the torch of science is characteristically Greek and appears in Plato. The letter thus reveals the neohumanistic love of the Greeks so characteristic of German Romanticism.

${ }^{44}$ See also Cantor to Klein (January 1883) quoted at the beginning of $\S 3$.
} 
"his first flame" (ibid., 124). ${ }^{45}$ Starting in 1885, and partly (it seems) as a consequence of disenchantment with the community of mathematicians, Cantor began establishing close links with theologians and philosophers. But, interestingly, he stated in another letter to Hermite of January 1894 that his approximation to Catholicism had begun with the First Vatican Council in $1870 .{ }^{46}$ Later on, the revival of Thomism and the new spirit of approximation to the sciences, impulsed by Pope Leo XIII from 1880, became attractive to the philosophically and metaphysically minded academic.

The articles written by Cantor from 1882 onward, particularly the Grundlagen and two later philosophical papers (among them 1887/88), made it clear that he was deeply involved with theological thinking. The point is reinforced by the large amount of correspondence he had with Catholic theologians, including Cardinals and even the Pope, in an attempt to influence official Vatican doctrines regarding actual infinity. This rapprochement to Catholicism may appear surprising in a Protestant by education, but on the one hand his mother was a Catholic (see Meschkowski 1983, 124), and above all the spirit of transgressing party boundaries seems to have been strong in Cantor, and perhaps also in his parents. He behaved analogously, from an early stage, when he decided to publish not only in the Journal of the Berlin mathematicians, but also in the Mathematische Annalen led by their "opposition."

\section{Intellectual context in Prussia: The debate on materialism}

Our understanding of Cantor's situation around 1870 would be very incomplete, however, if we failed to take into account the broader atmosphere of the period. The figures of Trendelenburg and Lotze, Cantor's philosophy professors at Berlin and Göttingen, already point us in that direction. The point is reinforced by Cantor's way of contrasting the "mechanical explanation" with the "organic theory of Nature" in the Grundlagen and elsewhere, and by his frequent condemnations of "empiricism, sensualism and materialism." We must, therefore, review some aspects of the scientific and cultural situation in Germany during the 1860s.

The second third of the nineteenth century, the time after Hegel's death, saw a steady increase in public esteem for the sciences, with a corresponding decline as concerned philosophy. This period leads us from the high point of German idealism to the age of positivism, scientism, and materialism. It was thus a period of crisis for philosophical thought, in which idealism in general, and Hegel in particular, were heavily under attack. This does not mean, however, that Romantic philosophical tendencies were abandoned. Quite the opposite: new proposals emerged that we may characterize as typically Romantic and metaphysical in spirit, meant as alternatives to positivism and materialism, but which at the same time denounced and tried to supersede the errors

\footnotetext{
45 As late as 1905 Cantor published a religious pamphlet, Ex Oriente Lux.

${ }^{46}$ Cantor to Hermite, 22 January 1894 (Meschkowski 1965, 514).
} 
of absolute idealism. It is noteworthy that both Trendelenburg and Lotze, different as their views were, belong to this group of post-idealistic Romantic philosophers.

The emergence of positivism, growing from its roots in the Enlightenment, is too well known to require detailed exposition here. Gustav Kirchhoff, professor of theoretical physics in Berlin, whose understanding of physical science was criticized by Cantor in the Grundlagen (see $\S 3$ ), offers a good example of German positivism among the physicists. Hermann von Helmholtz, another Berlin professor and first-rank intellectual figure, embodied the "skeptical" combination of positivistic and Kantian ideas that Cantor was criticizing so eagerly. Perhaps under the influence of those men, even Cantor's bête noire, Leopold Kronecker, would late in his life regard pure mathematics and arithmetic as "natural sciences" that describe natural phenomena. ${ }^{47}$ This was a scientific and philosophical trend emanating from Germany's most important university center, which Cantor would feel called to oppose in the strongest possible way. But even more important for our present purposes is the strong rise of materialism in Germany during the 1850s and 60s.

In the 1840s, a new physiology had emerged on the basis of strong assumptions of physico-chemical reductionism. It went under the name of "physiological mechanism." This trend was well represented in the famous Berlin group around Emil du BoisReymond and Hermann von Helmholtz, but its earliest exponent was Lotze himself, who - before becoming a professional philosopher - obtained a Ph.D. in medicine at Leipzig (1838) with a dissertation that already favored that viewpoint. ${ }^{48}$ Lotze affirmed the universal dominance of the mechanical point of view, and conceived of organic life as the sum of all non-vital processes taking place in the entire body. Later on, the studies of Helmholtz, du Bois-Reymond, and their colleagues, developed the mechanistic views in actual research.

This new trend in physiology ended up having a strong impact on popular views of science and the world. Mechanistic reductionism, combined with Feuerbach's philosophical "inversion" of idealism and critique of religion, ${ }^{49}$ led to the development of a strong German materialistic movement. This began in the 1840s and flourished in the 1850s, represented above all in the writings of Carl Vogt, but also in those of Moleschott, Büchner, and Czolbe, causing a great stir and reaching all classes of German society. ${ }^{50}$ Authors of the stature of the physiologist Rudolf Wagner, the

\footnotetext{
${ }^{47}$ See Kronecker's last lecture course (Boniface and Schappacher 2001, 226, in explicit reference to Kirchhoff, and 232-233).

48 These ideas became public in a handbook on general pathology (1842) and with a famous paper against the concept of vital force in Wagner's Handwörterbuch der Physiologie (Lotze 1843). The work of Lotze is discussed in Caneva 1993.

${ }^{49}$ Ludwig Feuerbach (1804-1872) belongs to the so-called "Hegelian left" and effected an "inversion" of Hegelianism. Das Wesen des Christentums (1841) offered a very influential anthropological interpretation of religion.

${ }^{50}$ On this movement, see the detailed study Gregory 1977. The most important writings were Vogt's Physiologische Briefe (1845-47), his Köhlerglaube und Wissenschaft (Natural science and coal maker's faith) 1854, Moleschott's Der
} 
chemist Justus von Liebig, and the above-mentioned Lotze felt obliged to intervene and question the credentials of these materialistic interpreters of scientific research. Generally speaking, academic scientists felt menaced by the unwelcome company of those "popular philosophers," who not only tried to establish a scientistic worldview while rejecting traditional religious beliefs, but also had socio-political reform as an important point in their agendas.

The heated debate on materialism created a very special atmosphere for the reception of Darwin's views on evolution by natural selection, published in 1859. The very first German work popularizing Darwinism was the Vorlesungen über den Menschen [Lectures on man] (1863) by Carl Vogt, which of course offered a blend of evolutionism and materialism. And the 1860s saw the emergence of Ernst Haeckel, a well-known zoologist and popular writer, professor at the University of Jena, who has been called a "fanatic evolutionary materialist" (Coleman 1971). ${ }^{51}$ Haeckel's popular writings, particularly the Naturgeschichte der Schöpfung [Natural history of the creation] (1868) and the Anthropogenie (1874), were very widely debated and helped to keep alive the flame of materialism.

Such worldviews inevitably clashed with the conceptions of bourgeois Germans, educated in the religious tradition and the Romantic cult of the soul. Their emergence revived Romantic and idealistic mistrust of mechanism as a soul-less, superficial and misleading approach to Nature. This may well have been the case with the young Cantor, whose father had given him a strong religious education, and obviously a successful one. In 1886, writing to C. A. Valson, he made a point of the intimate link between mechanics and materialism:

As you are aware, I know how to ponder the value of all efforts that go in the direction of elevating science to a more ideal standpoint.... On all this much could be said, but I limit myself to this, that in my opinion the great achievement of Newton, the Principia mathematica philosophiae naturalis, which is followed by all recent developments in mathematics and mathematical physics, has to be considered (due to gross metaphysical shortcomings and perversions of his system, and in spite of the well-meaning intentions of its author) as the real cause of present-day materialism and positivism, which has developed into a sort of monster and flaunts in the shiny garment of science.... it seems to me that the errors of modern skepticism, which regards itself as "positive" and links back to Newton, Kant, Comte and others, belong among the worst of all. ${ }^{52}$

In 1886 he wrote to Cardinal Franzelin that no system was farther from his convictions than pantheism, "if we except materialism, with which I have absolutely nothing in

Kreislauf des Lebens 1852, and Büchner's Kraft und Stoff (Force and matter) 1855. Their positions were famously qualified by Marx as "vulgar materialism."

${ }^{51}$ In time, Haeckel's evolutionary materialism evolved into the metaphysical doctrine of "monism."

52 Undated letter, probably 1886 (Purkert and Ilgauds 1987, 208-09). Valson had written biographies of Ampère and Cauchy. 
common." ${ }^{53}$ As we have seen, in the Grundlagen (1883) he criticized empiricism, sensualism, and skepticism - "sensualism" being a reference to the materialistic movement, since Feuerbach's ideas were classified under that label, and Czolbe's main book is the Neue Darstellung des Sensualismus (1855).

It is difficult, however, to trace the reactions of German academics to materialism and even Darwinism, for they tended to avoid explicit statements of opinion regarding such controversial issues. Public confrontation was frequently a source of discredit, and particularly dangerous for civil servants who depended very directly on decisions of the all-powerful Ministry. Cantor seems to have complied with this unwritten norm at least until 1885, when he abandoned hopes for a new position at Berlin or Göttingen. But it is very attractive to speculate on the possibility that Haeckel's virulent and much publicized ideas may have sparked Cantor's reaction in the 1860s. Although this might have been the case, I have only been able to find one document polemizing against the anti-Christian views of Haeckel (and Nietzsche too). In a letter of 1900 to Friedrich Loofs, professor of Church history at Halle, Cantor congratulated him for his book Anti-Haeckel:

I think it is very valuable that from now on the impudent appearance of a scientific character will be taken away, in front of the widest circles, from Haeckel's shameless attacks against Christianity.

The aristocratic aversion to bold polemics (so widespread in our circles!) had to give in considering such infamies....

I have only recently found an occasion to form a more precise image of the socalled Nietzschean philosophy and its dependence on Haeckel's monistic evolutionary philosophy. It finds among us an uncritical acceptance because of its stylistic appeal, which seems highly questionable to me considering the perverse contents and the Herostraticantichristian motives. ${ }^{54}$

Since he sent his Anti-Haeckel to Cantor as a gift, we may assume that Loofs was aware of his colleague's opposition to Haeckel's ideas from previous contacts. But of course this proves nothing about the situation in 1870 .

All taken together, the young Cantor was an adherent of traditional religious viewpoints, an admirer of the metaphysical system of Spinoza, and quite likely to have been horrified by the materialistic movement. This he came to regard as an outgrowth of mechanism, Kantian skepticism, and positivism. The genial side of his Romantic mind is revealed in that he did not remain content to entertain "higher beliefs," but tried to put mathematics at the service of the correct worldview - metaphysics,

${ }^{53}$ Cantor to Franzelin, 22 January 1886 (Meschkowski 1983, 126). As the reader will recall, pantheism was the main "danger" in Spinoza, a "sin" committed by Schelling and Hegel.

${ }^{54}$ Cantor to Loofs, 24 February 1900 (photographically reproduced in Meschkowski 1983, 292-93). 
science and religion all together. ${ }^{55}$ Cantor entertained hopes that by developing a new mathematical theory of point-sets he would be able to establish a deep and sounder foundation for an "organic theory of Nature," and thereby for the refutation of the materialistic trends. Seen in this light, and against the background of sections 1 and 2, we may safely conclude that the cultural and intellectual traditions of nineteenthcentury Germany played an important role in motivating his research.

\section{Denumerability, matter, the ether, and the continuum}

Cantor's thoughts on the architecture of his proposed organische Naturerklärung must have remained very sketchy, or else have disappeared. ${ }^{56}$ It seems clear, however, that his plan was to build up from the very bottom, starting with hypotheses about the inner constitution of matter and the ether. We shall first consider Cantor's general definition of the continuum and its possible role in the organic theory. Then, we will review some explicit proposals that he made public in 1885 , which concerned the open question of a grand unification of the laws of physics and chemistry.

\section{1.}

The idea that a theory of point-sets might be taken as the foundation for a new organic approach seems a rather natural assumption for Cantor's time. Nineteenth-century science accepted without question the idea that physical reality is continuous. Key new biological discoveries such as cell theory (inaugurated by Schwann and Schleiden shortly before Cantor's birth) implied that organic phenomena had to be analyzed and explained on a microscopic scale. This merely reinforced previous hypotheses that had emerged in the realms of physics (optics, electricity, magnetism) and chemistry (atomic theory). A long-standing tradition (going from Leibniz through Boscovich to Ampère, and even Riemann) suggested that one should employ hypotheses about dimensionless points - the simple elements of the continuum -, continuous transmission, and continuous functions, as the key to a true explanation of natural phenomena. Therefore one could conclude that only a more refined mathematics of the continuum would help solve these riddles. And point-sets can be defined, in general, as the subsets of the continuum - of any continuous domain, regardless of its number of dimensions.

Is there evidence that Cantor viewed the continuum in this light? We have already surveyed evidence for this conclusion. Another suggestive passage can be found in $\S 10$ of the Grundlagen, where Cantor offers a very interesting and pioneering abstract definition of the continuum. The concept of a continuous function had been carefully

\footnotetext{
${ }^{55}$ See Cantor 1887/88, 378, where he establishes this threefold connection and states that he has devoted himself primarily to metaphysics and mathematics for many years.

${ }^{56}$ Most of his papers disappeared in World War II (see Grattan-Guinness 1971).
} 
analyzed by Cauchy and Bolzano around 1820, but mathematicians had remained content with the assumption that the realm of magnitudes (resp. the real number system) is a continuous domain, without trying to analyze this concept of continuous domain. An early publication touching upon this point was Dedekind's study of 1872, but his approach was limited to the real line, a one-dimensional continuum. Cantor's approach in Grundlagen was more general and for this reason an important contribution to the emergence of topology.

Although Cantor mentions the many polemics on the proper conception of the continuum among philosophers, ${ }^{57}$ he quickly abandons the philosophical arena and proceeds to offer a "sober logical" definition and develop it "taking into account only the mathematical theory of sets." In the light of Cantor's views as presented above, I interpret this to mean that Cantor could have offered a fuller account, considering also the extra-mathematical implications of set theory and of his new definition.

According to Cantor, a subset of $\mathbb{R}^{n}$ is said to be a "continuum" if and only if it is a perfect, connected point-set (we shall not define those mathematical concepts here; see Cantor 1883, 194). According to this, the Euclidean space $\mathbb{R}^{n}$ is itself a continuum, but so too are many of its subdomains. Particularly relevant here is the level of generality which Cantor aimed to attain with his definition, for this can be related to the kind of continuous elements (figures) that one finds in Nature. As he made explicit in endnote 12, Cantor's definition does not presuppose anything about the dimensionality of each continuum - a domain consisting "of connected portions of several dimensions, like lines, surfaces, bodies, etc." can also be a continuum (ibid., 207-08).

It is interesting to consider this against the background of biological knowledge in his time. As we have seen ( $\S 3$ ), Cantor regarded cells as closed, continuous threedimensional domains in Euclidean space. The image of a three-dimensional body joined continuously to one-dimensional elements is suggested by microscopic objects like ciliated protozoans, e.g., a paramecium. Thus biological knowledge, and the foreseen applications of point-set theory to the "organic explanation of Nature," may have originated one of Cantor's criteria for the correctness of his general definition of continua.

Before abandoning this general topic, a clarification is in order. Cantor's interest in the continuum, in introducing abstract concepts and tools that could provide a complete analysis of continuous domains and point-sets, ended up leading to purely mathematical problems that, in turn, guided new phases of mathematical research. What I have in mind here is, above all, the famous Continuum Hypothesis $(\mathrm{CH}$, see $\S 1$ ), a key target for Cantor's research from its formulation in 1878 to the last paper that he was planning but did not publish in 1899. The Cantor-Bendixson theorem is related to $\mathrm{CH}$, and attempts to develop related strategies later on gave rise to descriptive set theory. Another outstanding problem was that of the invariance of

${ }^{57}$ In particular, the dispute whether our continuous world is built up of continuous elements (Aristotle) or of finite atoms (Lucretius) (Cantor 1883, 190-91). 
dimension, which links immediately with abstract topology. Thus in Cantor's mind the extra-mathematical motives combined with purely mathematical ones, but the next generation of mathematicians found enough open problems in this area that they could pursue point-set theory in purely mathematical terms.

\section{2.}

The question of the continuum had obvious connections with physics: the continuous medium or ether, through which light and in general electromagnetic waves were supposed to be transmitted, was then at the center of attention among physicists. Cantor proposed set-theoretical hypotheses related to this topic in a paper published by Acta Mathematica in 1885. With this he was developing a topic that he also discussed in letters of October and November 1884 to Mittag-Leffler. ${ }^{58}$ In this work he takes for granted that there are two specifically different kinds of matter, corporeal and ethereal matter.

Cantor was of the opinion that the results of mathematical physics, even the most brilliant among them, were unsatisfactory due in the last analysis to the lack of a correct understanding of "the constitution of matter, both ponderable and also the imponderable, the so-called ether." This shortcoming was, in his view, responsible for the irreducible division between partisans of atoms and partisans of the continuity hypothesis; however,

The results of my investigations, which in no way are purely speculative, but also take into account experiments and observations, is that one can still think of a third hypothesis, for which I have not yet found a name, a hypothesis which to some extent lies in between those two ... ${ }^{59}$

As regards corporeal matter, Cantor was an opponent of the atomic hypothesis, as he had already manifested in the Grundlagen (Cantor 1883, 179). In his view, any satisfactory theory of nature must begin with the assumption

that the ultimate, properly simple elements of matter are given in an actually infinite number, and regarding the spatial they must be considered as totally unextended and rigorously punctual. (Cantor 1885, 275; emphasis in the original)

According to him, this viewpoint was supported by physicists such as Faraday, Ampère, and Weber, and by Cauchy among the mathematicians. It is noteworthy that Wilhelm Weber had been Cantor's professor at Göttingen, in the summer term

\footnotetext{
${ }^{58}$ See already the indications, apropos of work on mathematical optics by Kowalevskaya, in a letter of October 1883 (Cantor 1991, 134-35). Further comments can be found in a letter to Kowaleskaya, 7 December 1884 (Dauben 1979, 310-11).

${ }^{59}$ Cantor to Mittag-Leffler, 20 October 1884 (Purkert and Ilgauds 1987, 203).
} 
of 1866. Cantor termed the simple elements "monads or units," in explicit reference to Leibniz's Monadologie. These monads were "created, and after creation [are] autonomous, indestructible elements, simple, extensionless, [and] endowed with forces." 60

Cantor proceeded to offer a precise model of the world of monads, a concrete geometrical and set-theoretical image of matter and the ether, free from any vagueness. His first physical hypothesis was that the set of corporeal monads is denumerable (of the first infinite cardinality, $\aleph_{0}$ ), while the set of ethereal monads has the power of the continuum (the second infinite cardinality, $\aleph_{1}$, according to $\mathrm{CH}$ ). ${ }^{61}$ Although, he said, the grounds for this hypothesis were complex, he offered as one of them the already-mentioned theorem of 1882, that continuous motion is possible in certain discontinuous spaces. Since the set of corporeal monads is denumerable, the remaining ether-filled portion of space complies with the assumptions of that theorem, and thus the ether enjoys

still a colossal space of play for continuous motion, by which all the phenomena of the transparency of bodies, as also those of radiant heat, of electric and magnetic influence, and of induction [Vertheilung], seem to obtain a natural and consistent basis. ${ }^{62}$

One may safely conjecture that another reason behind Cantor's claims was his other theorem of 1882, namely that any infinite set of non-intersecting spheres is denumerable, which we have seen applied to the number of cells in the world. For under the typical assumption that each corporeal monad, due to the forces with which it is endowed, possesses a certain sphere of influence within which no other corporeal atom may stand, ${ }^{63}$ his theorem establishes that the set of corporeal monads is denumerable.

As we see, features of Cantor's natural philosophy were present not only in his Grundlagen, but concealed also in his previous paper (1882), which according to the above is intimately related to Cantor's hypotheses. ${ }^{64}$ All of this establishes a smooth link between his innovative work on point-sets in the 1880s and the physical hypotheses advanced in 1885, which in turn had connections with Cantor's organicistic convictions.

A second hypothesis appearing in the letter to Mittag-Leffler and in 1885 depends on more sophisticated aspects of the set-theoretical ideas that Cantor entertained at this time. By the mid-1880s Cantor was considering a decomposition of infinite sets into disjoint "homogeneous" subsets (called "rests" and "inherences"). According to this,

\footnotetext{
${ }^{60}$ Cantor to Mittag-Leffler, 16 November 1884 (Purkert and Ilgauds 1987, 204; emphasis in the original).

${ }^{61}$ Cantor 1885, 276, and Cantor to Mittag-Leffler (Purkert and Ilgauds 1987, 205).

${ }^{62}$ Cantor to Mittag-Leffler, (Purkert and Ilgauds 1987, 205; emphasis in the original).

63 This assumption was regarded by Boscovich and many others as empirically proven, by the well-known fact of the impenetrability of material bodies.

${ }^{64}$ This paper is dated "Berlin, 31 March 1882," further confirming that Cantor's physical speculations were no product of the mental crisis in the spring of 1884 .
} 
the set $P$ of corporeal monads and the set $Q$ of ethereal monads would decompose into five subsets:

$$
\begin{aligned}
& P=\operatorname{Pr} \cup P i_{1} \\
& Q=Q r \cup Q i_{1} \cup Q i_{2},
\end{aligned}
$$

where $\operatorname{Pr}$ and $Q r$ are called the "rests" of their respective sets, $P i_{1}$ and $Q i_{1}$ are the "first inherences," and $Q i_{2}$ is the "second inherence" (Cantor 1885, 270-76). ${ }^{65}$ Cantor writes:

It will have to be decided whether the five essentially different parts, in which ethereal and corporeal matter is divided at any moment in time,... can perhaps correspond to essentially different modes of action or of manifestation of matter, like states of aggregation, chemical differences, light and heat, electricity, and magnetism. (Ibid., 276; emphasis in the original)

In the November letter to Mittag-Leffler he conjectured that this was so, and each of those parts possessed "a physical significance." He added that this second hypothesis for the monadic world did not carry with it a loss of the concept of volume, as he could show on the basis of his 1884 work on the so-called "outer content" of a point-set. ${ }^{66}$

In the November letter to Mittag-Leffler, Cantor did not forget to mention that the division of monads into two kinds was not only necessary for explaining inorganic phenomena, but also "up to a certain limit for [the explanation of] organic natural phenomena." As we see, Cantor thought it necessary, for his visionary reform of all of natural science, to start anew from the very bottom line.

6.3.

Strange as they may seem today, Cantor's speculations on Naturphilosophie and organicism certainly have their forerunners. While the connections to earlier authors such as Boscovich and Ampère are clear enough, we can also see links with important German scientists of the nineteenth century such as Wilhelm Weber, Fechner, and even Riemann. In the cases of Weber and Fechner, the connecting link is the monadological hypothesis, the assumption of a characteristic form of atomism that postulates strictly punctual atoms endowed with physical forces. The reader will recall that Cantor attended Weber's lectures in the summer of 1866 . Weber understood

\footnotetext{
${ }^{65} \mathrm{Pi}_{2}=\emptyset$ because $P$ is denumerable. On the reason why these sets are called "homogeneous," see Cantor 1885 , 264-65.

${ }^{66}$ This was important in the history of integration theory, being related to the later introduction of measure theory by Borel and Lebesgue (see Hawkins 1975). As we see, in Cantor's mind it was again linked to natural philosophy.
} 
the forces quite generally as relations between the atoms, whose form he assumed to be more complicated than his fellow scientists expected; this deviant feature seems related with his rejection of strict mechanism and, of course, of its materialist readings (see Norton Wise 1981). ${ }^{67}$ Cantor thought less about the forces and more about his new concept of transfinite set, hoping to find explanations for physical, chemical and biological phenomena in the different sets of monads.

But the most interesting comparison is with Bernhard Riemann, a key author in the emergence of modern mathematics, whose ideas left indelible traces in the fields of function theory, modern geometry and topology. ${ }^{68}$ Riemann too left manuscripts in which he tried to go beyond Newton's mechanical explanation, manuscripts published in the first edition of his Werke (1876) together with interesting speculations on psychology and on a teleological account of the organic world. Some of these ideas were clearly behind his epoch-making lecture on differential geometry (Riemann 1868). In a note that he must have written around 1853, Riemann indicated that his "main occupation" (!) ${ }^{69}$ was to develop "a new conception of the known natural laws" which could serve as the basis for a unified treatment of "heat, light, magnetism and electricity" (Riemann 1892, 507). While working on this project, Riemann advanced in the direction of field physics, but his untimely death left all these projects unfinished. The last paper on which he was working was a detailed attempt to analyze the mechanics of hearing. In it he openly criticized Helmholtz's views, as he opposed Helmholtz's positivistic tendencies and his mechanistic physiology.

There is no doubt that Riemann's physical work must be judged much deeper and more influential (indirectly, via the related mathematical concepts that he introduced) than Cantor's speculations about the physical and organic phenomena. Riemann did advanced work in electromagnetism and mathematical physics, and he created a differential geometry that was to become an essential ingredient of relativity theory. His contributions were based on detailed knowledge of experimental physics, obtained in Weber's laboratory, and on very abstract and novel mathematical conceptions. Still, we should not ignore the obvious similarities between both thinkers, which reveal common intellectual traditions typical of the nineteenth century. Both looked for grand new theories of natural phenomena, going beyond the mechanistic conception and incorporating elements of German Romantic thought, ${ }^{70}$ and both presented

\footnotetext{
${ }^{67}$ The Weber brothers and Fechner were close friends. On Gustav Theodor Fechner, experimental physicist, psycho-physiologist, and visionary philosopher, see Heidelberger 1993.

${ }^{68}$ Riemann's work had a clear impact upon Cantor's early research, particularly in areas that stood in the background of his development of set theory: trigonometric series, Riemannian geometry and topology (see Ferreirós 1999, chaps. II (sect. 6), V, and VI).

${ }^{69} \mathrm{He}$ also mentioned his work on function theory and mathematical physics, the basis for the fame he enjoyed in life and during the whole nineteenth century!

${ }^{70}$ In the case of Riemann, the main influence was the "realist" (i.e., anti-idealist) philosopher Johann Friedrich Herbart, and to some extent men like Fechner and the Göttingen physiologist Jakob Henle (Scholz 1982 and 2001).
} 
the typically Romantic trait of incorporating, as an essential ingredient of their reflections on physics, the consideration of "mental Nature" (psychology) and organic phenomena.

\section{Concluding remarks}

As I have said, we know of no further development of Cantor's speculations on Nature. In the late 1880s, he became more and more involved in defending the philosophical and theological underpinnings of his views, and apparently he did not come back to natural philosophy.

The Cantorian program of a unified, organic theory of all natural phenomena is strikingly in line with Romantic ideals. The champion of pure mathematics, who in Hilbert's metaphor - opened the doors of the mathematician's paradise, emerges in this light as a characteristic figure of the late Romantic movement. It has been said of Coleridge that his ambitious but unpublished life's work aimed at bringing together science, philosophy, poetry, and theology. If we regard pure mathematics, with Einstein, as the poetry of logical ideas, then that assertion may be applied to Cantor word for word. The connection between science, philosophy and theology, and the search for an "inside view" of Nature, ${ }^{71}$ joining the physical and the mental, were key ingredients of his worldview and his research programs.

The search for a grand unification of all "physical and mental" phenomena was a key goal of Cantor's. Emphasis upon the "unity of Nature," of all forces and phenomena, has frequently been regarded as a quintessential trait of German idealistic Naturphilosophie. This view, however, has recently been contested by Caneva, who casts doubt on the tendency to identify Naturphilosophie with the search for a unification of physical forces (Caneva 1993, chap. 7). What is typical of Romantic thinking, I believe, is only some more particular versions of the unity thesis, especially the assumption that unification can only be attained if one takes into account not just physical phenomena but also organic and mental phenomena. Thus it is not unity in general, but unity based on a reciprocal interaction between the physical and the mental, that reveals the clear impact of Romantic thought. This can be found in both Cantor and Riemann. ${ }^{72}$

The cases of Riemann and Cantor are also useful in correcting another simplistic assumption - the idea that Romantic views of Nature were always under the sign of the philosophy of Absolute idealism. Many of the best examples of philosophers that left important traces in the history of German science come from outside idealism, e.g., the Neo-Kantian Fries (crucial for botanist and cell theorist Schleiden) and the "realist" Herbart, enemy of the nineteenth-century idealists but of Leibnizian influences (and

\footnotetext{
${ }^{71}$ Cantor to Kowalevskaya, 7 December 1884 (Dauben 1979, 310).

72 At least in Riemann's early work of 1853. There are indications that his views may have changed during the following decade, coming closer to later scientific viewpoints.
} 
crucial for Riemann). In the case of Cantor, the most important impact came from older figures like Spinoza and Leibniz. All of these philosophers fall outside the category "idealism" as applied to Fichte, Schelling, Hegel, and their followers. ${ }^{73}$ The same is true of Kant, who influenced very many people, including Helmholtz.

In Kant's thought, his famous "transcendental idealism" is combined with the crucial element of "empirical realism." The attempt to balance and combine "empiricism" or "realism" with a measure of "idealism" - in a broad sense, sometimes Kantian, sometimes more metaphysical - seems to be a general feature of all the Romantic thinkers that concern us here. (By contrast, the Absolute idealism of Schelling and Hegel is characterized by blurring the boundary, so that the idealistic element invades and comes to dominate the empirical sphere too.) That general recipe, however, takes different concrete forms in the cases of Fries, Herbart, or Lotze. The reader will recall that the recipe is also clearly present in Cantor $(\S 3)$.

Generally speaking, then, one can be certain that the influence of philosophy on German scientists is a key trait of the nineteenth century, ${ }^{74}$ but that this question should be conceived in much broader and finer terms than the mere issue of idealistic Naturphilosophie. (This, of course, is not to deny the importance of idealistic impacts, like those on embryology and cell theory, or the influence of Schleiermacher on the mathematician Hermann Grassmann, ${ }^{75}$ but even in these cases a fine-tuned approach is required.) The topic calls for careful study, taking into consideration the effects of cultural traditions based on religion, on the German enlightenment, on literature and the arts, and on modern science, all of them embodied and peculiarly combined in the Romantic educational ideal of Bildung. ${ }^{76}$ No less important was the particular institutional, educational, and scientific setting of the faculties of philosophy at German universities.

Coming back to Cantor, I hope to have proven that his speculations on Nature, which many have considered as mere eccentricities, give a partial explanation of the general orientation of his work - of his quest for a mathematical theory of the infinite, the continuum, and point-sets. The evolution of his research, which cannot be sufficiently explained by an austere consideration of purely mathematical motives, becomes understandable when viewed against the broader context of German science around 1870 - the battle between materialism and "idealism" broadly conceived, the revival of philosophers such as Spinoza and Leibniz, and Cantor's hope to forge new mathematical tools on which to found a natural philosophy consistent with his metaphysical and religious beliefs.

\footnotetext{
${ }^{73}$ For Cantor's negative opinion about Hegel, see 1887/88, 391.

${ }^{74}$ One should add that the converse direction of influence was no less important, at least in the cases of Fries, Herbart, Lotze, or Fechner.

${ }^{75}$ For biology, see Coleman 1971, and L. S. Jacyna in Cunningham and Jardine 1990, 161-68. For Grassmann, see Lewis 1977.

${ }^{76}$ For Bildung and mathematics, see Schubring 1983 and 1991, Jahnke 1990.
} 
It has long been clear that Cantor's conception of the foundations of set theory was very different from the views held by most of his contemporaries. In one of his letters, he emphasized that "the foundation of his set-theoretical research" was "in diametrical opposition to" the assumptions of Dedekind. ${ }^{77}$ (It is my view that Dedekind is clearly more representative of the "majority view" at the time, as he had close affinities with men like Frege, Peano, Schröder, or the young Hilbert.) Behind that statement there was more than just an opinion concerning the foundations of mathematics, there were deep metaphysical, theological, and also "scientific" beliefs. Consider the unequivocal statement in a letter to the Italian mathematician Giuseppe Veronese:

Of hypotheses there is no question anywhere in my arithmetical investigations on the finite and the transfinite, but only of fathoming the real [things] existing in Nature. ${ }^{78}$

It has always been a surprising trait of Cantor's way of thinking that he seemed to be immune to skeptical doubts as to the real existence of infinite sets, particularly those of relatively high cardinalities. ${ }^{79}$ From what we have seen, Cantor's immunity was a natural consequence of his deep metaphysical conviction that transfinite sets exist really in God's mind and in Nature. Certainly this was, in his opinion, the case for sets of the cardinalities $\aleph_{0}$ - corporeal monads - and $\aleph_{1}$ - ethereal monads - , but he frequently entertained the view that higher cardinalities would also be found to exist in Nature. As we saw ( $\S 3$ ), Cantor expressed his conviction that "immanent" and "transient" existence always occur together, in the sense that an admissible, consistent concept "always also possesses in certain, and even infinitely many ways a transient reality" (Cantor 1883, 181, see also 205 n. 2). No wonder that men who did not share such strong assumptions, like most contemporaneous mathematicians, could not follow Cantor in his quest for the transfinite.

\section{Acknowledgments}

An early, rough version of this paper was read at the University of California at Berkeley (Colloquium Series, Office for History of Science and Technology) in 1993. I thank David Rowe, Erhard Scholz, and two unknown referees for their observations on a previous version of the final essay.

\footnotetext{
${ }^{77}$ Cantor to Hilbert, 15 November 1899 (Purkert and Ilgauds 1987, 154; emphasis in the original). Dedekind was also a crucial figure in the set-theoretical reshaping of mathematics, but he was a logicist (see Ferreirós 1996 and 1999).

${ }^{78}$ Cantor to Veronese, 17 November 1890 (Purkert and Ilgauds 1987, 202).

${ }^{79}$ Which (assuming $\mathrm{CH}$ ) could be said even of $\aleph_{3}$, but especially of $\aleph_{\omega}$ and other very large cardinals that he accepted without question. $\aleph_{\omega}$ and its followers are mentioned explicitly in a letter to Dedekind, 28 July 1899 , Cantor 1932, 443; their existence is also clearly affirmed in endnote 2 of the Grundlagen $(1883,205)$.
} 


\section{References}

Bölling, Reinhard. 1997. "Georg Cantor - Ausgewählte Aspekte seiner Biographie.” Jahresbericht der Deutschen Mathematiker-Vereinigung 99:49-82.

Boniface, Jacqueline and Norbert Schappacher. 2001. "'Sur le concept de nombre en mathématique': Cours inédit de Leopold Kronecker à Berlin (1891)." Revue d'Histoire des Mathématiques 7(2):207275.

Caneva, Kenneth L. 1993. Robert Mayer and the Conservation of Energy. Princeton: Princeton University Press.

Cantor, Georg. 1878. "Ein Beitrag zur Mannigfaltigkeitslehre." Journal für die reine und angewandte Mathematik 84:242-258. References are to reprint in Cantor 1932, 149-57.

Cantor, Georg. 1882. "Über unendliche, lineare Punktmannichfaltigkeiten, Nr. 3." Mathematische Annalen 20:113-121. References are to reprint in Cantor 1932, 139-244.

Cantor, Georg. 1883. Grundlagen einer allgemeinen Mannichfaltigkeitslehre. Ein mathematisch-philosophischer Versuch in der Lehre des Unendlichen. Leipzig: Teubner. Also (without preface) in Mathematische Annalen 21:545-591. References are to reprint in Cantor 1932, 165-208.

Cantor, Georg. 1885. "Über verschiedene Theoreme aus der Theorie der Punktmengen in einem $n$-fach ausgedehnten stetigen Raume $G_{n}$. Zweite Mitteilung." Acta Mathematica 7:105-24. References are to reprint in Cantor 1932, 261-76.

Cantor, Georg. 1887/88. "Mitteilungen zur Lehre vom Transfiniten." Zeitschrift für Philosophie und philosophische Kritik 91:81-125 and 92:240-265. References are to reprint in Cantor 1932, 378-439.

Cantor, Georg. 1932. Abhandlungen mathematischen und philosophischen Inhalts. Edited by E. Zermelo. Berlin: Springer.

Cantor, Georg. 1991. Georg Cantor: Briefe. Edited by H. Meschkowski and W. Nilson. Berlin: Springer.

Coleman, William. 1971. Biology in the Nineteenth Century. Cambridge: Cambridge University Press.

Cunningham, Andrew and Nicholas Jardine, eds. 1990. Romanticism and the Sciences. Cambridge: Cambridge University Press.

Dauben, Joseph. 1979. Georg Cantor. His Mathematics and Philosophy of the Infinite. Cambridge: Harvard University Press.

Dilthey, Wilhelm. [1860] 1972. "Review of Adolf Trendelenburg, Naturrecht auf dem Grunde der Ethik (Leipzig 1860)." Gesammelte Schriften (1972) 16:382-93. Göttingen: Vandenhoeck und Ruprecht.

Dugac, Pierre. 1973. "Eléments d'analyse de Karl Weierstrass." Archive for History of Exact Sciences 10:41176.

Dugac, Pierre. 1976. Richard Dedekind et les fondements des mathèmatiques (avec de nombreux textes inédites). Paris: Vrin.

Dugac, Pierre. 1984. "Georg Cantor et Henri Poincaré.” Bolletino di Storia delle Scienze Matematiche 4:65-96.

Fechner, Gustav Theodor. 1864. Über die physikalische und philosophische Atomenlehre. Leipzig: Mendehlsson.

Ferreirós, José. 1993. "On the Relations between Georg Cantor and Richard Dedekind." Historia Mathematica 20:343-63.

Ferreirós, José. 1995. “'What Fermented in Me for Years': Cantor's Discovery of Transfinite Numbers.” Historia Mathematica 22:33-42.

Ferreirós, José. 1996. "Traditional Logic and the Early History of Sets, 1854-1908." Archive for History of Exact Sciences 50:5-71.

Ferreirós, José. 1999. Labyrinth of Thought: A History of Set Theory and Its Role in Modern Mathematics. Basel/ Boston: Birkhäuser.

Fraenkel, Abraham. 1930. “Georg Cantor.” Jahresbericht der Deutschen Mathematiker-Vereinigung 39:189266. Shortened version in Cantor 1932.

Grattan-Guinness, Ivor. 1970. "An unpublished paper by Georg Cantor: Principien einer Theorie der Ordnungstypen. Erste Mitteilung.” Acta Mathematica 124:65-107. 
Grattan-Guinness, Ivor. 1971. "Towards a Biography of Georg Cantor." Annals of Science 27:345-391.

Grattan-Guinness, Ivor, ed. 1980. From the Calculus to Set Theory, 1630-1910. London: Duckworth.

Gregory, Frederick. 1977. Scientific Materialism in Nineteenth Century Germany. Dordrecht: Reidel.

Hallett, Michael. 1984. Cantorian Set Theory and Limitation of Size. Oxford: Clarendon Press.

Hawkins, Thomas W. 1975. Lebesgue's Theory of Integration: Its Origins and Development. New York: Chelsea.

Heidelberger, Michael. 1993. Die innere Seite der Natur. G. T. Fechners wissenschaftlich-philosophische Weltauffassung. Frankfurt: Klostermann.

Jahnke, Hans N. 1990. Mathematik und Bildung in der Humboldtschen Reform. Göttingen: Vandenhoeck und Ruprecht.

Jané, Ignacio. 1995. "The Role of the Absolute Infinite in Cantor's Conception of Set." Erkenntnis 42:375-402.

Jungnickel, Christa and Russell McCormach. 1986. Intellectual Mastery of Nature. Theoretical Physics from Ohm to Einstein. Vol. 1. Chicago: University of Chicago Press.

Leibniz, Gottfried Wilhelm. [1714] 1840, 1960. Monadologie. In Opera philosophica, edited by J. E. Erdmann. Berlin. Also in Die philosophischen Schriften, vol. 6, edited by C. J. Gerhardt, 607-23. Hildesheim: Olms.

Lewis, Albert C. 1977. "Hermann Grassmann's 1844 Ausdehnungslehre and Schleiermacher's Dialektik." Annals of Science 34:103-62.

Lotze, Hermann. 1843. "Leben, Lebenskraft." In Handwörterbuch der Physiologie, vol. 1, edited by R. Wagner, ix-lviii. Braunschweig: Vieweg.

Lotze, Hermann. [1856/64] [1876/80] 1885. Mikrokosmus. Ideen zur Naturgeschichte und Geschichte der Menschheit, Versuch einer Antropologie. 3 vols. Leipzig: Hirzel $\left(1876 / 80^{3}\right)$. English translation in 2 vols., 1885, Edinburgh: Clark.

Meschkowski, Herbert. 1965. “Aus den Briefbüchern Georg Cantors.” Archive for History of Exact Sciences 6:503-19.

Meschkowski, Herbert. 1983. Georg Cantor. Leben, Werk und Wirkung. Mannheim: Bibliographisches Institut.

Moore, Gregory H. 1989. “Towards a History of Cantor's Continuum Problem.” In The History of Modern Mathematics Vol. I, edited by D. Rowe y J. McCleary, 79-121. Boston/London: Academic Press.

Norton Wise, M. 1981. "German Concepts of Force, Energy, and the Electromagnetic Ether: 18451880." In Conceptions of Ether, edited by G. N. Cantor and M. J. S. Hodge, 269-307. Cambridge: Cambridge University Press.

Prantl, Carl von. 1894. "Lotze, Rudolf Hermann.” Allgemeine Deutsche Biographie vol. 19:290.

Purkert, Walter. 1986. "Georg Cantor und die Antinomien der Mengenlehre." Bulletin de la Société Mathématique de Belgique 38:313-27.

Purkert, Walter and Hans Joachim Ilgauds. 1987. Georg Cantor 1845-1918. Basel/Boston: Birkhäuser.

Riemann, Bernhard. [1868] [1892] 1996. "Über die Hypothesen, welche der Geometrie zu Grunde liegen." Abhandlungen der Königlichen Gesellschaft der Wissenschaften zu Göttingen 13: references to Riemann [1892]: 272-87. English translation 1996 in From Kant to Hilbert, vol. 2, edited by W. Ewald. Oxford University Press.

Riemann, Bernhard. [1876] 1892. "Fragmente philosophischen Inhalts." Riemann [1892]: 509-38.

Riemann, Bernhard. [1892] [1902] 1990. Gesammelte mathematische Werke und wissenschaftlicher Nachlass. Leipzig: Teubner. Reprinted with Nachträge (1902) and further additions (1990) in Berlin: Springer/ Teubner.

Scholz, Erhard. 1982. "Herbart's influence on Bernhard Riemann." Historia Mathematica 9:413-40.

Scholz, Erhard. 2001. "Bernhard Riemanns Auseinandersetzung mit der Herbartschen Philosophie." In Herbarts Kultursystem, edited by A. Hoeschen and L. Schneider, 163-183. Würzburg: Königshausen and Neumann.

Schubring, Gert. 1983. Die Entstehung des Mathematiklehrerberufs im 19. Jahrhundert. Weinheim/Basel: Beltz. Schubring, Gert, ed. 1991. "Eisamkeit und Freiheit" neu besichtigt. Stuttgart: F. Steiner. 